\title{
Performance of lactating suckler cows of diverse genetic merit and genotype under a seasonal pasture-based system
}

\author{
S. McCabe ${ }^{12}$, N. McHugh ${ }^{3}$, N.E. O'Connell ${ }^{2}$, R. Prendiville ${ }^{1 \dagger}$
}

${ }^{1}$ Livestock Systems Research Department, Animal and Grassland Research and Innovation Centre, Teagasc, Grange, Dunsany, Co. Meath, C15PW93, Ireland

2Institute for Global Food Security, School of Biological Sciences, Queens University Belfast, Belfast, BT9 7BL, Ireland

${ }^{3}$ Teagasc, Animal and Grassland Research and Innovation Centre, Moorepark, Fermoy, Co. Cork, P61C996, Ireland

Abstract

The objective of this study was to investigate the effect of genetic merit of the national Irish maternal index and genotype (i.e. beef vs. beef $\times$ dairy [BDX]) of beef cows and subsequent performance of their progeny. With the exception that high genetic merit cows produced $0.57 \mathrm{~kg}$ more milk and tended to have 0.04 of a lower body condition score (BCS), no significant differences were observed between cows of diverse genetic merit. Differences between contrasting cow genotype were apparent. Beef cows were $50 \mathrm{~kg}$ heavier and had a BCS 0.27 greater than $B D X$ cows. The BDX cows produced $1.67 \mathrm{~kg}$ more milk and had a greater 24-d submission rate than beef cows. Calves generated from BDX cows were $19 \mathrm{~kg}$ heavier at weaning and were worth $€ 51$ more than progeny generated from beef cows. Beef cow progeny, however, had 0.77 of a greater conformation score at slaughter than BDX. While differences were observed across cows of different replacement strategies, results from the current study showed that genetic selection for national maternal index had no effect on the overall performance of suckler cows in a pasture-based spring-calving system.

Keywords

Breed $\cdot$ genetic merit $\bullet$ pasture $\cdot$ progeny $\cdot$ suckler

\section{Introduction}

Approximately $70 \%$ of beef herds in Ireland operate low input pasture-based production systems where cows calve in the spring period of February to May (Berry \& Evans, 2014). Grass growth commences in March, peaks in May and then declines to November (Drennan et al., 2005). Therefore, in a seasonal production system such as Ireland, calving coincides with the start of grass growth. This system of production is based on utilising high levels of grass at grazing, with grassland contributing up to $97 \%$ of the total ruminant diet (Keating \& O'Kiely, 2000), as well as being the main feed source (grazed or conserved) for suckler beef systems in Europe (Lawrence et al., 2012). Beef cows should produce a calf with a good weight for age and exhibit high levels of reproductive efficiency from low input pasturebased systems (McGee et al., 2005a; Murphy et al., 2008a). Success of the system is then driven by key variables such as stocking rate, turnout date and mean calving date (Crosson et al., 2014).
The national Irish beef herd comprises $75 \%$ beef breeds and $25 \%$ beef breed $\times$ dairy breed (BDX) sucklers (McCabe et al., 2018). Typically beef cows are a terminal type female, predominantly late-maturing crossbred (DAFM, 2016/17) with Limousin (LM) crossbred cows being the dominant breed at $37 \%$ of the national herd, followed by Charolais $(\mathrm{CH})$, Aberdeen Angus (AA) and Simmental (SI) at 20\%, 12\% and $10 \%$, respectively. Inefficiencies within the Irish beef suckler herd relating to milk yield and reproductive performance have been clearly acknowledged (Berry \& Evans, 2014). This facilitated the need for development of a specialised national genetic index (ICBF, 2017) using Irish maternal genetic evaluations to assist producers in identifying animals suitable for breeding replacements that would be superior for maternal traits (McHugh et al., 2014). Kluyts et al. (2004) stated that development of breeding objectives must be centred around accurate information on the environment, markets and traits of interest and should be followed by strong actions to develop 
meaningful breeding goals that will effectively improve animal genetics. The important role of maternal traits within cattle breeding goals has been outlined by Cartwright (1970) and Koch (1972), with maternal breeding programmes previously established internationally to facilitate their selection (Ménissier et al., 1982; Trus and Wilton, 1988; Roughsedge et al., 2005).

Previous studies have investigated components of suckler cow production systems such as replacement heifer management (Funston \& Deutscher, 2004), calving and reproductive performance (Drennan \& Berry, 2006), cow mortality (Mõtus \& Emanuelson, 2017), the effect of milk yield on progeny performance, both pre-weaning (McGee et al., 2005a; Murphy et al., 2008a) and post-weaning (Fiss \& Wilton, 1993), suckler cow feed intake and performance (Lawrence et al., 2013), and economic efficiency (Taylor et al., 2018). Managing heifers to calve for the first time at $2 \mathrm{yr}$ of age was reported to be the most efficient and economical strategy for primiparous cows (Crosson \& McGee, 2012). Suckler cow genotype comparisons demonstrated that due to greater milk yields, BDX cows, particularly LM $\times$ Holstein-Friesian (FR), produced heavier weanlings, with this advantage following through to slaughter (Murphy et al., 2008b). Differences in reproductive performance between cow genotypes have varied across studies, some reported beef cows to be superior (Osoro \& Wright, 1992) and others reported BDX cows to be superior (Newman \& Deland, 1991), with Drennan \& Berry (2006) stating that reproductive performance is more dependent on management and nutrition than breed type. To date, however, no study has compared a suckler cowcalf system in its entirety, including progeny weaning and slaughter data.

The Replacement Index established in Ireland, as described by McCabe et al. (2017), serves as a tool to assist farmers in breeding goals to optimise suckler beef production and to retain the most profitable females for breeding, but to date has not been validated at farm level. Therefore, the objective of this study was to determine the effect of genetic merit and genotype on overall cow and calf performance within a calfto-weanling and a calf-to-beef pasture-based system over a 4-yr period.

\section{Materials and methods}

This experiment was carried out at Teagasc, Grange Beef Research Centre, County Meath, Ireland. Animal procedures undertaken in this experiment were approved by the Teagasc Animal Ethics Committee and licensed by the Health Products Regulatory Authority in accordance with the protection of animals used for scientific purposes (Directive 2010/63/EU). This study began in spring 2013 when heifers were bred for the first time, with data generated over four grazing seasons, 2014-2017.

Beef heifers of diverse genetic merit for maternal traits were selected for the study at c. 8 mo of age (MO) from beef suckler and dairy herds, with the aim of being bred for the first time at c. 15 mo. Heifers from the suckler herd were bred from either AA, Hereford ( $\mathrm{HE}), \mathrm{LM}, \mathrm{CH}$, SI or Belgian Blue (BB) cows and FR cows only from the dairy herd. Heifers were generated from AA or LM sires of high reliability $(>70 \%)$ for the Replacement Index. Common sires were used on the beef and dairy herd. In total, 199 cows over four lactations were available: 109 high genetic merit $(\mathrm{HIGH}), 90$ low genetic merit (LOW); 102 beef and 97 BDX cows. The Replacement Index value for HIGH and LOW when the study commenced was $€ 117$ ( $\pm € 30)$ and $€ 56$ ( $\pm € 31$ ), respectively, and remained constant for the duration of the study. The mean predicted transmitting ability (PTA) for HIGH and LOW groups for the main traits of interest is outlined in Table 1.

Cows were housed in early November for the non-lactating winter period in a conventional slatted indoor housing system. Cows were grouped in pens of seven based on their expected calving date and offered a moderate quality grass silage ad libitum diet plus dry cow minerals (David Taylor Animal Nutrition, Westmeath, Ireland) at a rate of $100 \mathrm{~g} / \mathrm{d}$.

Cows and their calves were turned out to pasture during March and April, and grazed in four groups: two beef and two BDX. Groups were managed on a rotational grazing system as described by O'Donovan et al. (2002) on a predominantly perennial ryegrass (Lolium perenne) sward. Mineral supplementation was supplied to groups in 2014 and 2015 via mineral lick block (Co-op Source, Cork, Ireland) and then via Terra Liquid Mineral Dispensing Unit in the water supply (Terra Liquid Minerals, Athy, Co. Kildare, Ireland) during 2016 and 2017 for long-term supply of trace elements, including calcined magnesite, and vitamins to aid in long-term mineral balance and also during periods of fast grass growth to assist in reducing the risk of hypomagnesaemia.

\section{Calving performance}

Cows were removed from the slatted housing to individual straw-bedded pens $1 \mathrm{~d}$ prior to calving on the basis of their expected calving date and visible indication of the onset of calving (Wehrend et al., 2006). Calving difficulty was recorded on a scale of $1-4$, as outlined by McHugh et al. (2014), postparturition along with calf details such as sex, birth weight and perinatal mortality, which was defined as calves that died within $48 \mathrm{~h}$ of birth. Total calf mortality was defined as any calf that died from birth to weaning. Due to an outbreak of cryptosporidium, calf mortality data from year 1 (2014) were not included in the analysis resulting in 371 data records available. Cows remained in individual pens with their calf for 
Table 1: Replacement Index value breakdown and mean predicted transmitting ability descriptive statistics for high and low genetic merit animals

\begin{tabular}{|c|c|c|c|}
\hline & \multicolumn{2}{|c|}{ Genetic merit } & \multirow{2}{*}{$\begin{array}{l}\text { Difference } \\
\text { High vs. Lou }\end{array}$} \\
\hline & High & Low & \\
\hline Replacement Index $(€)$ & $117 \pm 30$ & $56 \pm 31$ & 61 \\
\hline Maternal cow traits $(€)$ & $408 \pm 166$ & $115 \pm 186$ & 293 \\
\hline Maternal progeny traits $(€)$ & $173 \pm 90$ & $162 \pm 78$ & 11 \\
\hline Calving difficulty score (\%) & $3.32 \pm 1.42$ & $4.87 \pm 1.66$ & 1.55 \\
\hline Cow weight $(\mathrm{kg})$ & $14.23 \pm 13.08$ & $23.70 \pm 14.16$ & 9.5 \\
\hline Gestation length (d) & $0.58 \pm 1.52$ & $1.71 \pm 1.33$ & 1.13 \\
\hline Age at first calving (d) & $-16.35 \pm 9.49$ & $-7.95 \pm 7.93$ & 8.4 \\
\hline Maternal weaning weight $(\mathrm{kg})$ & $11.67 \pm 5.27$ & $5.74 \pm 5.87$ & 5.93 \\
\hline Direct carcass weight $(\mathrm{kg})$ & $6.77 \pm 8.83$ & $10.15 \pm 7.67$ & 3.38 \\
\hline Feed intake $(\mathrm{kg})$ & $0.003 \pm 0.204$ & $-0.033 \pm 0.196$ & 0.036 \\
\hline
\end{tabular}

a minimum of $2 \mathrm{~d}$ before either being moved to group pens with a creep area or turned out to pasture.

\section{Reproductive performance}

Fertility data were available from a total of 429 observations. Breeding commenced in late April each year and continued for $13 \mathrm{wk}$. Tail paint and vasectomised bulls were used as heat detection aids to facilitate artificial insemination (AI). An experienced Al technician was used throughout the course of this study. In the first two breeding seasons (2013 and 2014), Al was utilised for the first 6 wk of the breeding season with stock bulls introduced thereafter. Bulls were allocated to one grazing group per week and rotated subsequently. In 2015 and 2016, 9 wk of Al was conducted with stock bulls introduced for the final 4 wk. Semen quality for each sire used was tested as outlined by Prendiville et al. (2011). Only AA and LM sires that were in the top $20 \%$ for the Irish national terminal index were used. Cows not observed in oestrus after $28 \mathrm{~d}$ inseminated were scanned via transrectal ultrasonography using an Aloka 210D * II, 7.5 MH3 scanner (Aloka Ltd., Tokyo, Japan) to confirm pregnancy status. Subsequently, all cows were examined again at day 60 post-insemination and at $150 \mathrm{~d}$ after the start of the breeding season. All cows scanned not pregnant at 150 $\mathrm{d}$ were culled from the study after weaning was completed.

Measures of reproductive efficiency utilised included: submission rate in the first $24 \mathrm{~d}$ of the breeding season (Serv24), calving to service interval (CSI), pregnancy rate to first service based on ultrasonic imaging at day 150 (PREG1), proportion of cows pregnant in the first $6 \mathrm{wk}$ of the breeding season based on ultrasonic imaging at day 150 (6wkICR), proportion of cows pregnant at the end of the breeding season based on the ultrasonic imaging at day 150 (PREGRATE), calving to conception interval based on results of ultrasonic imaging at day 150 (CCl), number of services per cow (NoSERV) and calving interval (CIV).

\section{Production performance}

Cow live weight (body weight [BW]) was recorded every 3 wk using a calibrated "Titan Weigh Crate" (O'Donovan's Engineering, Cork, Ireland) combined with Tru-Test software (Auckland, New Zealand). Body condition score (BCS) was measured concurrently to $\mathrm{BW}$ by a single evaluator on a scale of 0-5 (Lowman et al., 1976). Cow BW and BCS were also recorded at calving and when the breeding season commenced. Estimates of cow milk yield were determined twice in 2014 (at $120 \pm 23.5$ and $156 \pm 23.5 \mathrm{~d}$ in milk [DIM]), and three times in 2015 (at $52 \pm 5.6,131 \pm 34.5$ and $184 \pm 23.1$ DIM) and 2016 (at $50 \pm 4.9,127 \pm 30.5$ and $171 \pm 28.7 \mathrm{DIM}$ ) using the weighsuckle-weigh technique (McGee et al., 2005a) as modified by McCabe et al. (2017).

\section{Progeny performance}

Data were available on 424 calf birth weights and 389 weaning weights (WWs). Calf performance was monitored according to average daily gain (ADG) which was determined after each 3 -wk weighing. Calves were allowed access to "creep graze" (Drennan, 1971; Drennan \& McGee, 2009) 4 mo prior to weaning, and were offered $1 \mathrm{~kg}$ concentrate DM per day prior to separation from the cow. Calves were weaned using the gradual weaning technique (Enríquez et al., 2011). Calf WW was recorded at an average of $227 \pm 29 \mathrm{~d}$ of age over four lactations. Calf quality was assessed at weaning on a scale of $1-5$ ( $1=$ very poor; $5=$ exceptional $)$ as well as calf docility ( 1 = very quiet; 5 = very difficult) by a trained technician according to the scale outlined in the Irish Suckler Cow Quality and Welfare Scheme 2008 (ICBF, 2013). Calf 
value was determined for $3 \mathrm{yr}$, from 2015 to 2017, by three independent assessors who were representative of the export and auctioneering markets of the Irish beef industry.

Carcass data were available from 284 calves born from 2014 to 2016. A 2 (gender) $\times 2$ (slaughter ages) factorial arrangement of treatments was assigned. Heifers were either slaughtered at $19 \mathrm{MO}$ finished off pasture or at $21 \mathrm{MO}$ finished indoors on a grass silage ad libitum diet supplemented with $5 \mathrm{~kg}$ concentrates DM/d for $72 \mathrm{~d}$ preslaughter. Male calves were castrated in mid-October each year and slaughtered as steers at either $21 \mathrm{MO}$ or $24 \mathrm{MO}$ and followed the same finishing system as $21 \mathrm{MO}$ heifers. Carcass conformation and carcass fat were scored using the European Union beef carcass classification (EUROP) grades transformed into a 1-15-point linear scale as outlined by Hickey et al. (2007).

\section{Sward measurements}

Throughout the grazing periods of March to November, sward measurements and analysis were carried out as described by McCabe et al. (2019). Briefly, 40 pre- and post-grazing sward heights per paddock were determined using a rising plate meter (Filip's Manual Plate Meter, Jenquip, New Zealand). Herbage yield was determined and chemical analysis conducted in vitro for acid detergent fibre (ADF; Clancy and Wilson, 1966), crude protein (CP), neutral detergent fibre (NDF), organic matter digestibility (OMD; Morgan et al., 1989) and ash.

\section{Statistical analysis}

The effect of genotype (beef or BDX), cow genetic merit (HIGH or LOW) and the interaction between genetic merit and genotype on BW, BCS, calving difficulty and calving day of year, calving to first service (CFS), CCI, CIV, NoSERV, calves per cow, milk yield and progeny performance traits was estimated using a linear mixed model in PROC HPMIXED (version 9.3; SAS Inst. Inc., Cary, NC, USA). Cow genetic merit (HIGH or LOW), genotype (beef and BDX), their interaction, cow breed (AA and LM), calf sex, year and parity were included as fixed effects in all models. The sire of the calf PTA for carcass weight was also included as a fixed effect in the model for WW, ADG, carcass weight and kill-out proportion. Sire of the calf PTA for carcass conformation was also included in the model for carcass fat and conformation and sire of the calf PTA for calving difficulty was included in the model for calving difficulty. For calf value, evaluator was included as a fixed effect and age was included in the model for all calf performance and carcass traits. Cow was included as a random effect which also accounted for the repeated records per cow.

The effect of genotype (i.e. BDX or beef cows), cow genetic index (HIGH or LOW) and their interaction on age at first calving (AFC) was quantified using a fixed-effects model in PROC GLM (version 9.3; SAS Inst. Inc., Cary, NC, USA). Cow genetic merit (HIGH or LOW), genotype (beef and BDX), the interaction between genetic merit and genotype, breed (AA and LM), calf sex and year were included as fixed effects in all models.

Binary variables of perinatal mortality, total mortality, Serv24, PREG1, 6wkICR, PREGRATE and survival were analysed using logistic regression in PROC GENMOD (version 9.3; SAS Inst. Inc., Cary, NC, USA). Cow genetic merit (HIGH or LOW), genotype (beef and BDX), the interaction between genetic merit and genotype, breed (AA and LM), calf sex, year and parity were included as fixed effects in all models.

\section{Results}

\section{Sward measurements}

Pre- and post-grazing sward surface heights, pre-grazing herbage yield and chemical composition of the herbage throughout the grazing seasons of the current study are presented in Table 2

\section{Calving performance}

No difference was observed across genotype or genetic merit for calving date; mean calving date was 18 March. Calf birth weight and calving difficulty were also similar across genotype and genetic merit (Table 3), with all cows averaging calf birth weight of $44 \mathrm{~kg}$ and a calving difficulty score of 1.70. No difference was observed between $\mathrm{HIGH}$ and LOW or beef and BDX cows for perinatal or total calf mortality (Table 4).

Table 2: Pre- and post-grazing sward surface heights, pre-grazing herbage yield and chemical composition of grass offered to cows

\begin{tabular}{lcc}
\hline Item & Mean & s.d. \\
\hline Pre-grazing sward surface height $(\mathrm{cm})$ & 11.9 & 2.57 \\
Post-grazing sward surface height $(\mathrm{cm})$ & 4.7 & 1.1 \\
Pre-grazing herbage yield $(\mathrm{kg} \mathrm{DM} / \mathrm{ha})$ & 2206 & 738.5 \\
Crude ash (g/kg DM) & 104 & 15.9 \\
CP (g/kg DM) & 199 & 30.5 \\
ADF (g/kg DM) & 243 & 39.7 \\
OMD (g/kg OM) & 780 & 48.4 \\
NDF (g/kg DM) & 492 & 101 \\
UFL/kg DM ${ }^{1}$ & 0.95 & \\
\hline
\end{tabular}

$11 \mathrm{UFL}$ is defined as the net energy content of $1 \mathrm{~kg}$ of standard barley for milk production (O'Mara, 1997).

$\mathrm{ADF}=$ acid detergent fibre, $\mathrm{CP}=$ crude protein, $\mathrm{NDF}=$ neutral detergent fibre, $\mathrm{OM}=$ organic matter, $\mathrm{OMD}=$ organic matter digestibility. 
Table 3: Effect of cow genetic merit, genotype and their interaction on calving date, calf birth weight, calving difficulty and reproductive performance

\begin{tabular}{|c|c|c|c|c|c|c|c|c|c|}
\hline & \multicolumn{2}{|c|}{ Genetic merit (GM) } & \multicolumn{4}{|c|}{ Genotype (G) } & \multicolumn{3}{|c|}{$P$ value } \\
\hline & High & Low & s.e. ${ }^{1}$ & $\mathrm{BDX}^{2}$ & Beef & s.e. ${ }^{1}$ & GM & G & $G M \times G^{3}$ \\
\hline Calving date & 16 March & 17 March & 2.3 & 15 March & 19 March & 2.3 & & & \\
\hline Calf birth weight $(\mathrm{kg})$ & 44 & 45 & 0.6 & 44 & 45 & 0.69 & & & \\
\hline Calving difficulty score (1-4) & 1.69 & 1.71 & 0.094 & 1.63 & 1.77 & 0.093 & & & \\
\hline Age at first calving (d) & 759 & 758 & 3.9 & 755 & 762 & 3.7 & & & \\
\hline Calving to first service (d) & 61 & 63 & 1.8 & 62 & 62 & 1.8 & & & \\
\hline Calving to conception (d) & 77 & 77 & 1.5 & 77 & 76 & 1.5 & & & \\
\hline Number of services/cow & 1.74 & 1.58 & 0.079 & 1.70 & 1.62 & 0.079 & & & \\
\hline Calving interval (d) & 363 & 362 & 1.57 & 362 & 362 & 1.5 & & & \\
\hline Calves per cow (no.) & 2.57 & 2.53 & 0.029 & 2.55 & 2.55 & 0.028 & & & \\
\hline
\end{tabular}

${ }^{1}$ Weighted standard error of the mean.

${ }^{2}$ Beef $x$ dairy cows.

${ }^{3}$ Genetic merit $\times$ genotype interaction.

Table 4: Cow genotype, genetic merit and their interaction odds ratios (upper and lower confidence intervals in parenthesis) with the associated $P$ value, for calf mortality, reproductive variables and cow survival

\begin{tabular}{|c|c|c|c|c|c|}
\hline & \multicolumn{2}{|c|}{ Genetic merit (GM) $^{1}$} & \multicolumn{2}{|c|}{ Genotype (G) ${ }^{2}$} & \multirow{2}{*}{$\begin{array}{l}\mathrm{GM} \times \mathrm{G}^{3} \\
P \text { value }\end{array}$} \\
\hline & Odds ratio & $P$ value & Odds ratio & $P$ value & \\
\hline Perinatal mortality & $0.39(0.12,1.21)$ & & $0.42(0.13,1.31)$ & & \\
\hline Total mortality & $0.66(0.31,1.38)$ & & $0.72(0.34,1.50)$ & & \\
\hline Submission rate $(24 \mathrm{~d})$ & $1.37(0.89,2.09)$ & & $2.01(1.32,3.04)$ & $* *$ & \\
\hline Pregnant to first service & $0.73(0.49,1.10)$ & & $0.87(0.59,1.29)$ & & \\
\hline Six-week in-calf rate & $0.92(0.61,1.40)$ & & $1.20(0.80,1.79)$ & & \\
\hline Pregnancy rate & $1.26(0.69,2.33)$ & & $1.51(0.83,2.74)$ & & \\
\hline Cow survival & $1.13(0.70,1.83)$ & & $1.33(0.84,2.12)$ & & * \\
\hline
\end{tabular}

${ }^{1}$ Relative to a low genetic merit cow for each trait.

${ }^{2}$ Relative to a beef cow for each trait.

${ }^{3}$ Genetic merit $\times$ genotype interaction.

${ }^{*}=P<0.05,{ }^{* *}=P<0.01$.

\section{Reproductive performance and survival}

Cows calved for the first time at 24.5MO (Table 3; $P>0.05$ ).

Calving interval was similar across both genotype and genetic merit. An interaction between genetic merit and genotype was observed for cow survival, with BDX LOW cows 1.35 times (95\% confidence interval: $1.70-2.60 ; P<0.05)$ more likely to survive to the subsequent lactation compared to BDX HIGH cows. No difference was found across beef cows of contrasting genetic merit (Table 4).

No difference was observed between genotype and genetic merit for any of the following reproductive variables investigated: CFS, CCI, NoSERV, calves per cow (Table 3), PREG1, 6wkICR or PREGRATE (Table 4). While Serv24 was similar for HIGH and LOW groups, BDX cows had a greater submission rate in the first $24 \mathrm{~d}$ than beef cows $(P$ $<0.01$ ).

\section{Production performance}

No difference was observed in BW between HIGH and LOW cows. However, BCS tended $(P=0.063)$ to be 0.04 units greater for LOW than HIGH cows (Table 5 ). Beef cows were $50 \mathrm{~kg}$ heavier and had a 0.27 greater BCS than BDX cows $(P$ $<0.001$ ). Corresponding differences between beef and BDX cows were $35 \mathrm{~kg}$ and 0.16 of a BCS at calving $(P<0.001)$ and $41 \mathrm{~kg}$ and 0.21 of a BCS at the onset of the breeding season $(P<0.001)$. 
Table 5: Effect of cow genetic merit, genotype and their interaction on production performance

\begin{tabular}{|c|c|c|c|c|c|c|c|c|c|}
\hline & \multicolumn{2}{|c|}{ Genetic merit (GM) } & \multicolumn{4}{|c|}{ Genotype (G) } & \multicolumn{3}{|c|}{$P$ value } \\
\hline & High & Low & s.e. ${ }^{1}$ & $\mathrm{BDX}^{2}$ & Beef & s.e. ${ }^{1}$ & GM & G & $G M \times G^{3}$ \\
\hline Live weight - year $(\mathrm{kg})$ & 659 & 663 & 8.8 & 636 & 686 & 8.0 & & *** & \\
\hline Live weight - calving (kg) & 629 & 626 & 7.7 & 610 & 645 & 7.2 & & *** & \\
\hline Live weight - breeding $(\mathrm{kg})$ & 633 & 632 & 9.2 & 612 & 653 & 8.3 & & *** & \\
\hline BCS - year $(0-5)^{4}$ & 2.92 & 2.96 & 0.018 & 2.80 & 3.07 & 0.017 & $=0.063$ & *** & \\
\hline BCS - calving $(0-5)^{4}$ & 2.39 & 2.42 & 0.017 & 2.33 & 2.49 & 0.016 & & *** & \\
\hline BCS - breeding $(0-5)^{4}$ & 2.81 & 2.83 & 0.023 & 2.71 & 2.92 & 0.022 & & *** & \\
\hline Milk yield (kg) & 8.19 & 7.62 & 0.152 & 8.74 & 7.07 & 0.162 & ** & $* * *$ & \\
\hline
\end{tabular}

${ }^{1}$ Weighted standard error of the mean.

${ }^{2}$ Beef $x$ dairy cows.

${ }^{3}$ Genetic merit $\times$ genotype interaction.

${ }^{4}$ Body condition score range: $0=$ emaciated, $5=$ extremely fat.

${ }^{* *}=P<0.01,{ }^{* * *}=P<0.001$.

The HIGH cows produced $0.57 \mathrm{~kg} / \mathrm{d}$ more milk than the LOW cows $(P<0.01)$, and an additional $1.67 \mathrm{~kg}$ was produced by BDX over the beef cows $(P<0.001)$.

\section{Progeny performance}

For all progeny performance traits investigated, both preweaning and carcass traits, no differences were observed across cow genetic merit (Table 6). Calves generated from BDX cows had a $0.08 \mathrm{~kg}$ greater ADG $(P<0.001)$ during the calf rearing period and were $19 \mathrm{~kg}$ heavier at weaning than calves from beef cows $(P<0.001)$. Calf quality and docility were similar for both BDX and beef cow progeny. An interaction was observed between genetic merit and genotype for calf value, where progeny from beef HIGH achieved an additional $€ 37$ at weaning than beef LOW $(P<0.05)$. No difference was observed between progeny of BDX cows of contrasting genetic merit. Progeny produced from beef cows had 0.77 greater conformation $(P<0.001)$ than BDX cows. However, all other carcass traits were similar across genotype (Table 6).

\section{Discussion}

The majority of calves in Ireland are suckled during the first grazing season and weaned at c. $8 \mathrm{MO}$ in October/November before housing for the winter (Drennan et al., 2005). Suckler beef systems can be generally dichotomised into two systems

Table 6: Effect of cow genetic merit, genotype and their interaction on progeny performance

\begin{tabular}{|c|c|c|c|c|c|c|c|c|c|}
\hline & \multicolumn{2}{|c|}{ Genetic merit (GM) } & \multicolumn{4}{|c|}{ Genotype (G) } & \multicolumn{3}{|c|}{$P$ value } \\
\hline & High & Low & s.e. ${ }^{1}$ & $\mathrm{BDX}^{2}$ & Beef & s.e. ${ }^{1}$ & GM & G & $\mathbf{G M} \times \mathbf{G}^{3}$ \\
\hline Calf weaning weight $(\mathrm{kg})$ & 295 & 295 & 4.1 & 304 & 285 & 4.1 & & $* * *$ & \\
\hline Average daily gain $(\mathrm{kg} / \mathrm{d})$ & 1.14 & 1.12 & 0.015 & 1.17 & 1.09 & 0.015 & & $* * *$ & \\
\hline Calf quality (1-5) & 3.36 & 3.29 & 0.067 & 3.31 & 3.34 & 0.067 & & & \\
\hline Calf docility (1-5) & 1.63 & 1.65 & 0.037 & 1.66 & 1.62 & 0.037 & & & \\
\hline Calf value $(€)$ & 729 & 712 & 11.2 & 746 & 695 & 9.4 & & $* * *$ & * \\
\hline Slaughter live weight (kg) & 648 & 646 & 7.2 & 649 & 645 & 7.1 & & & \\
\hline Carcass weight $(\mathrm{kg})$ & 350 & 349 & 3.8 & 349 & 350 & 3.7 & & & \\
\hline Conformation score (1-15) & 7.50 & 7.57 & 0.140 & 7.15 & 7.92 & 0.138 & & $* * *$ & \\
\hline Fat score (1-15) & 9.32 & 9.14 & 0.164 & 9.38 & 9.03 & 0.157 & & & \\
\hline Kill-out proportion (g/kg) & 541 & 542 & 0.4 & 540 & 544 & 0.3 & & & \\
\hline
\end{tabular}

${ }^{1}$ Weighted standard error of the mean.

${ }^{2}$ Beef $x$ dairy cows.

${ }^{3}$ Genetic merit $\times$ genotype interaction.

${ }^{*}=P<0.05,{ }^{* * *}=P<0.001$. 
depending on the outcome of the progeny, whether sold live, predominantly as weanlings, for further feeding (calf to weaning) or sold as finished animals for slaughter in a calf-tobeef system (Taylor et al., 2018). Within all systems, profitable suckler cow production is dependent on cows exhibiting high levels of reproductive efficiency while producing a heavy calf from a predominantly grazed grass diet (Crosson et al., 2014), thus increasing beef live weight output per hectare which is a key driver of profitability (Taylor et al., 2018). Therefore, the objective of this study was to evaluate the performance of beef suckler cows diverse in genetic merit for maternal traits and also to determine if differences in progeny performance exist, whilst also comparing the performance of two contrasting replacement strategies (cow genotypes) under pasture-based systems.

\section{Calving performance}

Calving difficulty is a consequence of calf birth weight being incompatible with the pelvic opening of the cow or too great a proportion of the cows' own BW (Naazie et al., 1989; Zaborski et al., 2009). The absence of significant differences in calf birth weight across contrasting cow genotypes in the current study may therefore have resulted in the lack of calving difficulty observed. This is in contrast to previous studies that outlined greater potential for beef cows to incur calving difficulty than BDX cows (Hickson et al., 2006; McCabe et al., 2018), or studies by Barlow et al. (1994) and Murphy et al. (2008a) which deemed them intermediate between certain beef breeds.

In contrast to the results from the current study, the Irish national suckler herd reported calf perinatal mortality of approximately 9\% (McCabe et al., 2018), while Baker et al. (1990) reported that the average calf survival across nine beef and two dairy breeds in New Zealand was $8 \%$. Calf mortality has been reported to be influenced by cow breed; Laster \& Gregory (1973) and Baker et al. (1990) reported 5.5\% and 4\% for BDX relative to $14.5 \%$ and $14 \%$ for $\mathrm{CH}$ crossbred cows, respectively. However, results from the current study are in agreement with those reported by Reynolds et al. (1986) who found no difference across a range of beef and BDX breeds. Azzam et al. (1993) reported that calf mortality is five times more likely to occur where a cow encountered calving difficulty as opposed to those that required no assistance. Similarly, McCabe et al. (2018) found that when dystocia was included in the model for perinatal mortality using logistic regression in PROC GENMOD, it rendered no difference in perinatal mortality, highlighting that difficulties incurred during calving have the biggest impact on subsequent calf survival.

\section{Reproductive performance and survival}

Age at puberty and farm management decisions are two components that influence AFC. McHugh et al. (2014) outlined that many Irish producers elect for heifers to calve at $36 \mathrm{mo}$ rather than managing heifers to become pubertal for breeding at 15 mo (Patterson et al., 2000). This practice exists across Europe, where Dákay et al. (2006) observed a range of 2.03-3.51 yr for AFC across a variety of beef breeds in Hungary. However, research by Pinney et al. (1972) and Chapman et al. (1978) showed that heifers with an AFC of 24 mo weaned 0.4 and 0.9 more calves over their lifetime than those with an AFC of 36 mo. Newman \& Deland (1991) showed that BDX heifers calve approximately a week earlier than beef, which Prendiville \& McHugh (2014) have attributed to an earlier onset of puberty. However, this difference was not observed in the current study.

The practice of culling cows for being non-pregnant or failure to wean a calf mainly dictates survival rates of sucklers (Morris et al., 1993), followed by calving success indicators such as AFC, dystocia, stillbirth or abortion (Mõtus \& Emanuelson, 2017). The lack of significant differences across these traits in the current study may explain the comparable cow survival rates observed in the present study.

Disparities exist in the literature as to whether BDX or beef cows are superior in terms of reproductive efficiency. Nelson \& Beavers (1982) highlighted that mature BDX cows had superior reproductive performance to mature beef cows, Butson et al. (1980) reported them comparable and Drennan \& Berry (2006) stated that nutrition was the limiting factor rather than breed. Reproductive efficiency in suckler cows is defined as achieving high submission rates and high conception rates per service (Crowe, 2008). The BDX cows in the current study were superior in terms of submission rate in the first $24 \mathrm{~d}$; however, overall pregnancy rate was similar across genotypes. As outlined by Recoules et al. (2013), reproductive performance of the sucker herd is dependent on cow nutrition, with postpartum ovarian activity being the product mainly of pre-partum nutrition. Cows in the current study had a suitable BCS at calving (between 2 and 3 ) to achieve $80 \%$ probability of calving within the first $42 \mathrm{~d}$ of the following calving season (Drennan \& Berry, 2006), maintaining their maternal productivity.

\section{Production performance}

Chemical composition of the grass herbage available to all animals was of high quality (McEvoy et al., 2010). Consistent with the findings of the present study, Murphy et al. (2008a) reported a $64-\mathrm{kg}$ and $0.45-\mathrm{BCS}$ score difference at housing and a 49-kg and 0.37-BCS score difference after calving for LM cows compared to LM $\times$ FR. The lower BCS of BDX is a direct breed consequence as dairy breeds are more likely to deposit fat in the abdominal cavity while beef breeds deposit fat subcutaneously (Truscott et al., 1983). In agreement with Murphy et al. (2008a) and McGee et al. (2005b), the greater BW gain of beef cows at pasture than BDX cows may be a result of their lower milk yield and energy requirements. 
While BDX cows exhibited superior production performance in terms of calf WW than beef cows in the current study, McCabe et al. (2018) reported that the greater production levels of BDX cows and subsequent extrapolated efficiency measures were attributed to a requirement for greater intakes. Fraga et al. (2016) and Minick et al. (2001) have corroborated how selection for milk can result in increased milk yield, which was observed in the additional $0.57 \mathrm{~kg}$ for $\mathrm{HIGH}$ cows in the present study.

\section{Progeny performance}

Weaning weight is a product of production system implemented and the age at which calves are weaned. Average WW using livestock auctions and commercial farm data reported by McHugh et al. (2011) is $1 \mathrm{~kg}$ lighter than WW recorded in the current study for BDX progeny, while Syrucek et al. (2017) reported WW of male calves in the Czech Republic similar $(289 \mathrm{~kg})$ to beef progeny in the current study. French specialised beef cattle breeds of $\mathrm{CH}$, LM, Blonde d'Aquitaine and Maine-Anjou calf WW ranged from 15 to $38 \mathrm{~kg}$ lighter than the average WW in the current study (Phocas \& Laloë, 2004). As no difference was observed in the quality of the progeny, the greater WW is reflected in the greater value of BDX progeny (McHugh et al., 2011).

Previous work has shown that live weight differences at weaning are likely to remain to slaughter (Drennan \& McGee, 2004; Murphy et al., 2008b). Results from the current study are in contrast with these findings as no difference in BW at slaughter was observed between progeny of beef and BDX. While Drennan \& McGee (2004) and Murphy et al. (2008b) deemed the progeny of beef cows to be unable to compensate for the difference post-weaning, differences in feed efficiency between beef and BDX animals (Archer et al., 1999) may be one explanation for improved performance of beef progeny post-weaning. Lewis et al. (1990) demonstrated that when progeny received lower levels of milk in the preweaning phase, a period of compensatory growth occurred post-weaning. The superior carcass conformation attained by progeny from beef cows in the present study compared to BDX progeny is in agreement with that found by Kirkland et al. (2004) and Drennan et al. (2008).

Previous research conducted by McHugh et al. (2014) demonstrated that genetic selection for improved maternal performance would materialise in an improved phenotypic performance. However, results from the current study clearly demonstrate that genetic selection for maternal traits utilising the Replacement Index had no main significant effect on overall performance. This may be attributed to how the national validation study examined phenotypic performance from Irish beef herds on an individual trait basis, where herd-year-season contemporary groups were also formed separately for each trait. In contrast, the current study followed the same animals through their lifetime performance for all traits examined and while ranked on overall genetic index value, were not necessarily of the same ranking for each individual trait. It must also be noted that despite the large dataset utilised in the national validation study, McHugh et al. (2014) stated that the incremental change in the phenotype per unit change in EBV (estimated breeding value) was not always as large as expected. Therefore, it is unsurprising that the considerably smaller statistical power of the experimental herd in this study was unable to detect significant statistical differences. Nonetheless, utilising genetic indexes in the suckler herd is an important resource, as demonstrated by Clarke et al. (2009).

\section{Conclusion}

Replacement strategy (cow genotype) has one of the biggest impacts on profitability within the suckler beef herd. Results from the current study showed that suckler cows of contrasting genotype performed similarly across a multitude of traits, with those generated from crossbreeding with dairy cows producing heavier calves at weaning via greater levels of milk production.

Results from the current study showed that genetic selection for maternal traits utilising a national maternal index (Replacement Index) had no effect on the overall performance of suckler cows in a pasture-based spring-calving system. Nonetheless, utilising genetic indexes in the suckler herd is an important resource and phenotypic performance generated from the current study can be included in future genetic evaluations to improve the reliability of genetic values.

\section{Acknowledgements}

The technical assistance of Edward Mulligan and the diligent work of the farm staff at Teagasc, Grange (Ireland) are gratefully acknowledged.

\section{Conflicts of interest}

The authors wish to confirm that there are no known conflicts of interest associated with this publication and there has been no significant financial support for this work that could have influenced its outcome.

\section{References}

Archer, J.A., Richardson, E.C., Herd, R.M. and Arthur, P.F. 1999. Potential for selection to improve efficiency of feed use in beef 
cattle: a review. Australian Journal of Agricultural Research 50: 147-162.

Azzam, S., Kinder, J., Nielsen, M.K., Werth, L., Gregory, K., Cundiff, L.V. and Koch, R. 1993. Environmental effects on neonatal mortality of beef calves. Journal of Animal Science 71: 282-290.

Baker, R., Carter, A., Morris, C. and Johnson, D. 1990. Evaluation of eleven cattle breeds for crossbred beef production: performance of progeny up to 13 months of age. Animal Science 50: 63-77.

Barlow, R., Hearnshaw, H., Arthur, P. and Darnell, R. 1994. Evaluation of Hereford and first-cross cows on three pasture systems. I. Calf growth and reproductive performance of young cows. The Journal of Agricultural Science 122: 121-129.

Berry, D.P. and Evans, R.D. 2014. Genetics of reproductive performance in seasonal calving beef cows and its association with performance traits. Journal of Animal Science 92: 1412-1422.

Butson, S., Berg, R. and Hardin, R. 1980. Factors influencing weaning weights of range beef and dairy-beef calves. Canadian Journal of Animal Science 60: 727-742.

Cartwright, T.C. 1970. Selection criteria for beef cattle for the Future. Journal of Animal Science 30: 706-711.

Chapman, H.D., Young, J.M., Morrison, E. and Edwards, N.C. 1978. Differences in lifetime productivity of Herefords calving first at 2 and 3 years of age. Journal of Animal Science 46: 1159-1162.

Clancy, M.J. and Wilson, R.K., 1966. Development and application of a new chemical method for predicting the digestibility and intake of herbage samples. Proceedings of the 10th International Grassland Congress, Helsinki, Finland, pages 445-452.

Clarke, A.M., Drennan, M.J., McGee, M., Kenny, D.A., Evans, R.D. and Berry, D.P. 2009. Intake, growth and carcass traits in male progeny of sires differing in genetic merit for beef production. Animal 3: 791-801.

Crosson, P. and McGee, M. 2012. Bioeconomic modelling of alternative replacement heifer policies for suckler beef production systems. Proceedings of the Agricultural Research Forum, Tullamore, Co Offaly, Ireland, page 47.

Crosson, P., McGee, M. and Prendiville, R. 2014. Profit drivers for suckler and dairy calf to beef systems. Proceedings of the Joint IGFA/Teagasc Nutrition Event, Portlaoise, Ireland.

Crowe, M. 2008. Resumption of ovarian cyclicity in post-partum beef and dairy cows. Reproduction in Domestic Animals 43: 20-28.

DAFM 2016/17. Annual Review and Outlook for Agriculture, Food and the Marine, page 145 .

Dákay, I., Márton, D., Keller, K., Fördös, A., Török, M. and Szabó, F. 2006. Study on the age at first calving and the longevity of beef cows. Journal of Central European Agriculture 7: 377-388.

Drennan, M.J. 1971. Single-Suckled beef production: 2. Influence of stocking rate during the grazing season, creep grazing of the calf and double-suckling on calf performance. Irish Journal of Agricultural Research 10: 297-305.

Drennan, M.J. and Berry, D.P. 2006. Factors affecting body condition score, live weight and reproductive performance in spring-calving suckler cows. Irish Journal of Agricultural and Food Research 45: 25-38.

Drennan, M.J. and McGee, M. 2004. Effect of suckler cow genotype and nutrition level during the winter on voluntary intake and performance and on the growth and slaughter characteristics of their progeny. Irish Journal of Agricultural and Food Research 43: 185-199.

Drennan, M.J. and McGee, M. 2009. Performance of spring-calving beef suckler cows and their progeny to slaughter on intensive and extensive grassland management systems. Livestock Science 120: $1-12$.

Drennan, M.J., Carson, A. and Crosse, S. 2005. Overview of animal production from pastures in Ireland. Utilisation of Grazed Grass in Temperate Animal Systems: Proceedings of a Satellite Workshop of the XXth International Grassland XXth International Grassland Congress, Cork, Ireland, pages 19-35.

Drennan, M.J., McGee, M. and Keane, M. 2008. The value of muscular and skeletal scores in the live animal and carcass classification scores as indicators of carcass composition in cattle. Animal 2: 752-760.

Enríquez, D., Hötzel, M.J. and Ungerfeld, R. 2011. Minimising the stress of weaning of beef calves: a review. Acta Veterinaria Scandinavica 53: 28.

Fiss, C.F. and Wilton, J.W. 1993. Contribution of breed, cow weight, and milk yield to the preweaning, feedlot, and carcass traits of calves in three beef breeding systems. Journal of Animal Science 71: 2874-2884.

Fraga, F.R., Lopez-Villalobos, N., Martin, N., Kenyon, P., Morris, S. and Hickson, R. 2016. Intake of milk and pasture and growth rate of calves reared by cows with high or low potential for milk production. Animal Production Science 58: 523-529.

Funston, R.N. and Deutscher, G.H. 2004. Comparison of target breeding weight and breeding date for replacement beef heifers and effects on subsequent reproduction and calf performance. Journal of Animal Science 82: 3094-3099.

Hickey, J., Keane, M., Kenny, D., Cromie, A. and Veerkamp, R. 2007. Genetic parameters for EUROP carcass traits within different groups of cattle in Ireland. Journal of Animal Science 85: 314-321.

Hickson, R., Morris, S., Kenyon, P. and Lopez-Villalobos, N. 2006. Dystocia in beef heifers: a review of genetic and nutritional influences. New Zealand Veterinary Journal 54: 256-264.

ICBF, 2013. "Discussion Re Suckler Schemes". Irish Cattle Breeding Federation. Available online: https://www.icbf.com/wp/wp-content/ uploads/2013/06/Suckler_Scheme_201207.pdf [Accessed 8 June 2020], 23 pages.

ICBF, 2017. "Euro-Star Index Explained". Irish Cattle Breeding Federation. Available online: https://www.icbf.com/wp/?p=9778 [Accessed 8 June 2020].

Keating, T. and O'Kiely, P. 2000. Comparison of old permanent grassland, Lolium perenne and Lolium multiflorum swards grown for silage: 1. Effects on beef production per hectare. Irish Journal of Agricultural and Food Research 39: 1-24. 
Kirkland, R., Keady, T., Ingram, P., Steen, R., Comerford, J., Patterson, D. and Mayne, C. 2004. Beef from the suckler herd: 1. Effect of origin of dam genotype on maternal characteristics and performance of progeny. Proceedings of the British Society of Animal Science, York, UK, page 34.

Kluyts, J., Neser, F. and Bradfield, M. 2004. Development of breeding objectives for beef cattle breeding: derivation of economic values: review article. South African Journal of Animal Science 33: 142-158.

Koch, R.M. 1972. The role of maternal effects in animal breeding: VI. Maternal effects in beef cattle. Journal of Animal Science 35: 1316-1323.

Laster, D.B. and Gregory, K.E. 1973. Factors influencing periand early postnatal calf mortality. Journal of Animal Science 37: 1092-1097.

Lawrence, P., Kenny, D., Earley, B. and McGee, M. 2012. Grazed grass herbage intake and performance of beef heifers with predetermined phenotypic residual feed intake classification. Animal 6: 1648.

Lawrence, P., Kenny, D.A., Earley, B. and McGee, M. 2013. Intake of conserved and grazed grass and performance traits in beef suckler cows differing in phenotypic residual feed intake. Livestock Science 152: 154-166.

Lewis, J., Klopfenstein, T., Stock, R. and Nielsen, M. 1990. Evaluation of intensive vs extensive systems of beef production and the effect of level of beef cow milk production on postweaning performance. Journal of Animal Science 68: 2517-2524.

Lowman, B.G., Scott, N.A. and Somerville, S.H. 1976. "Condition Scoring of Cattle". Edinburgh School of Agriculture, Edinburgh, page 31 .

McCabe, S., McHugh, N. and Prendiville, R. 2017. Evaluation of production efficiencies among primiparous suckler cows of diverse genetic index at pasture. Advances in Animal Biosciences 8: s55-s59.

McCabe, S., Prendiville, R., Evans, R., O'Connell, N. and McHugh, N. 2018. Effect of cow replacement strategy on cow and calf performance in the beef herd. Animal 13: 631-639.

McCabe, S, McHugh, N, O'Connell, NE and Prendiville, R 2019. Comparative grazing behaviour of lactating suckler cows of contrasting genetic merit and genotype. Livestock Science 220: 129-136.

McEvoy, M., Delaby, L., Murphy, J., Boland, T. and O'Donovan, M. 2010. Effect of herbage mass and allowance on sward characteristics, milk production, intake and rumen volatile fatty acid concentration. Grass Forage Science 65: 335-347.

McGee, M., Drennan, M.J. and Caffrey, P.J. 2005a. Effect of suckler cow genotype on milk yield and pre-weaning calf performance. Irish Journal of Agricultural and Food Research 44: 185-194.

McGee, M., Drennan, M.J. and Caffrey, P.J. 2005b. Effect of suckler cow genotype on energy requirements and performance in winter and subsequently at pasture. Irish Journal of Agricultural and Food Research 44: 157-171.
McHugh, N., Cromie, A., Evans, R. and Berry, D. 2014. Validation of national genetic evaluations for maternal beef cattle traits using Irish field data. Journal of Animal Science 92: 1423-1432.

McHugh, N., Evans, R.D., Amer, P.R., Fahey, A.G. and Berry, D.P. 2011. Genetic parameters for cattle price and body weight from routinely collected data at livestock auctions and commercial farms. Journal of Animal Science 89: 23-39.

Ménissier, F., Foulley, J. and Sapa, J. 1982. Selection of French beef breeds for purebreeding. Proceedings of the 2nd World Congregation of Genetics and Applied Livestock Production, Madrid, Spain, page 314.

Minick, J.A., Buchanan, D.S. and Rupert, S.D. 2001. Milk production of crossbred daughters of high- and low-milk EPD Angus and Hereford bulls. Journal of Animal Science 79: 1386-1393.

Morgan, D.J., Stakelum, G. and Dwyer, J. 1989. Modified neutral detergent cellulase digestibility procedure for use with the 'Fibertec' system. Irish Journal of Agricultural Research 28: 91-92.

Morris, C.A., Baker, R.L., Cullen, N.G., Hickey, S.M. and Wilson, J.A. 1993. Genetic analyses of cow lifetime production up to 12 mating years in crossbred beef cattle. Animal Science 57: 29-36.

Mõtus, K. and Emanuelson, U. 2017. Risk factors for on-farm mortality in beef suckler cows under extensive keeping management. Research in Veterinary Science 113: 5-12.

Murphy, B.M., Drennan, M.J., O'Mara, F.P. and McGee, M. 2008a. Performance and feed intake of five beef suckler cow genotypes and pre-weaning growth of their progeny. Irish Journal of Agricultural and Food Research 47: 13-25.

Murphy, B.M., Drennan, M.J., O'Mara, F.P. and McGee, M. 2008b. Post-weaning growth, ultrasound and skeletal measurements, muscularity scores and carcass traits and composition of progeny of five beef suckler cow genotypes. Irish Journal of Agricultural and Food Research 47: 27-40.

Naazie, A., Makarechian, M. and Berg, R. 1989. Factors influencing calving difficulty in beef heifers. Journal of Animal Science 67: 3243-3249.

Nelson, L.A. and Beavers, G.D. 1982. Beef $\times$ beef and dairy $\times$ beef females mated to Angus and Charolais sires. I. Pregnancy rate, dystocia and birth weight. Journal of Animal Science 54: 1138-1149.

Newman, S. and Deland, M. 1991. Lifetime productivity of crossbred cows. 2. Age and weight at first oestrus, calf birth weight, assisted calvings, calving interval and reproduction rate. Australian Journal of Experimental Agriculture 31: 293-300.

O'Donovan, M., Connolly, J., Dillon, P., Rath, M. and Stakelum, G. 2002. Visual assessment of herbage mass. Irish Journal of Agricultural and Food Research 41: 201-211.

O'Mara, F. 1997. A net energy system for cattle and sheep. Department of Animal Science and Production, Faculty of Agriculture, University College Dublin, Belfield, Dublin.

Osoro, K. and Wright, I. 1992. The effect of body condition, live weight, breed, age, calf performance, and calving date on reproductive 
performance of spring-calving beef cows. Journal of Animal Science 70: 1661-1666.

Patterson, D.J., Wood, S.L. and Randle, R.F. 2000. Procedures that support reproductive management of replacement beef heifers. Journal of Animal Science 77: 1-15.

Phocas, F. and Laloë, D. 2004. Genetic parameters for birth and weaning traits in French specialized beef cattle breeds. Livestock Production Science 89: 121-128.

Pinney, D.O., Stephens, D. and Pope, L. 1972. Lifetime effects of winter supplemental feed level and age at first parturition on range beef cows. Journal of Animal Science 34: 1067-1074.

Prendiville, R. and McHugh, N. 2014. Live weight, body condition score at breeding, onset of puberty and age at first calving for heifers of high and low maternal index. Proceedings of the Agricultural Research Forum, Tullamore, page 117.

Prendiville, R., Shalloo, L., Pierce, K. and Buckley, F. 2011. Comparative performance and economic appraisal of HolsteinFriesian, Jersey and Jersey $\times$ Holstein-Friesian cows under seasonal pasture-based management. Irish Journal of Agricultural and Food Research 50: 123-140.

Recoules, E., De La Torre, A., Agabriel, J., Egal, D. and Blanc, F. 2013. Subcutaneous body lipids affect cyclicity and estrus behavior in primiparous Charolais cows. Animal Reproduction Science 140: 115-123.

Reynolds, W.L., Bellows, R.A., Urick, J.J. and Knapp, B.W. 1986. Crossing beef $\times$ beef and beef $\times$ Brown Swiss: pregnancy rate, calf survival, weaning age and rate. Journal of Animal Science 63: 8-16.

Roughsedge, T., Amer, P.R., Thompson, R. and Simm, G. 2005. Development of a maternal breeding goal and tools to select for this goal in UK beef production. Animal Science 81: 221-232.

Syrucek, J., Kvapilik, J., Barton, L., Vacek, M. and Stadnik, L. 2017. Economic efficiency of suckler cow herds in the Czech Republic. Agricultural Economics (Zemědělská Ekonomika) 63: 34-42.

Taylor, R.F., McGee, M., Kelly, A.K., Grant, J. and Crosson, P. 2018. A comparison of production systems and identification of profit drivers for Irish suckler beef farms. International Journal of Agricultural Management 6: 100-110.

Trus, D. and Wilton, J.W. 1988. Genetic parameters for maternal traits in beef cattle. Canadian Journal of Animal Science 68: 119-128.

Truscott, T., Wood, J. and MacFie, H. 1983. Fat deposition in Hereford and Friesian steers: 1. Body composition and partitioning of fat between depots. The Journal of Agricultural Science 100: 257-270.

Wehrend, A., Hofmann, E., Failing, K. and Bostedt, H. 2006. Behaviour during the first stage of labour in cattle: Influence of parity and dystocia. Applied Animal Behaviour Science 100: 164-170.

Zaborski, D., Grzesiak, W., Szatkowska, I., Dybus, A., Muszynska, M. and Jedrzejczak, M. 2009. Factors affecting dystocia in cattle. Reproduction in Domestic Animals 44: 540-551. 